ORIGINAL ARTICLE

\title{
Cancer incidence in the Swedish leather tanning industry: updated findings 1958-99
}

\section{Z Mikoczy, L Hagmar}

See end of article for authors' affiliations

.....................

Correspondence to: Mr Z Mikoczy, Department of Occupational and Environmental Medicine, Lund University Hospital, SE-221 85 Lund, Sweden; zoli.mikoczy@ymed.lu.se

Accepted

17 December 2004
Aims: To assess how a 10 year extension of the follow up period affected cancer incidence in the Swedish leather tanning cohort.

Methods: A cohort of 2027 tannery workers (of which 482 were women) who had been employed for at least one year between 1900 and 1989 at one of three Swedish leather tanneries, was established. The start of observation varied between 1958 and 1966 for the three plants. Through linkage with the Swedish Cancer Registry, incident cancer cases were recorded up to 1999. Cause specific expected cancer incidence was calculated for 1958-99 based on calendar year, sex, and five year age group specific incidence rates for the counties where the plants had been located. Altogether 56022 person-years at risk were generated.

Results: A total of 351 incident cancer cases were observed compared to 302 expected, which resulted in an increased standardised incidence ratio (SIR) of 1.16 (95\% $\mathrm{Cl} 1.04$ to 1.29). An enhanced risk for prostate cancer was observed (SIR 1.44, 95\% Cl 1.10 to 1.86), mainly attributable to the later part of the observation period (1990-99). In this updated analysis the previously observed risk excess for soft tissue sarcomas was no longer significant (SIR 2.62, 95\% Cl 0.96 to 5.70). For multiple myelomas and sinonasal cancer the slight non-significant excesses remained, still based on very few cases.

Conclusions: The increased risk for prostate cancer in the present study might be a chance finding, but is noteworthy, since it is in acccordance with the finding of increased SIR for prostate cancer among leather workers in another recent Swedish study. Moreover, excess risks for prostate cancer among farmers have been reported, indicating pesticides as possible causative agents. Leather tanners have also been exposed to pesticides.
W ork in leather tanning and processing may involve exposure to a wide range of chemicals. Some of these are carcinogens or suspected carcinogens, such as hexavalent chromium salts, vegetable tannins, chlorophenols, aniline dyes, formaldehyde, methyl mercury, arsenic, benzene, and chlorinated organic solvents. ${ }^{1}$ Furthermore, exposure to leather dust, which has caused increased risks for sinonasal cancer in the shoe and boot making industry, ${ }^{2}$ might also be substantial in the leather tanning industry. There have also been indications of such an association for tannery workers. ${ }^{3}$

Numerous associations between leather tanning and site specific cancer have been reported, although there are considerable inconsistencies between studies. Increased lung cancer risks have in some studies been associated with leather tanning. ${ }^{4-10}$ Weak associations between employment in the leather tanning industry and bladder cancer have been shown in some studies, ${ }^{11-13}$ but not in all. ${ }^{10} 14{ }^{15}$ In a single study an increased incidence of renal cancer was reported. ${ }^{16}$ Increased risk for pancreatic cancer has been shown in a Swedish case-referent study, ${ }^{9}$ but no such association was found in cohort studies. ${ }^{212}{ }^{16}$ An excess of soft tissue sarcomas (STS) among leather tanners has been reported, ${ }^{217}$ including a significantly increased incidence based on five cases, observed in the first report from this Swedish cohort of leather tannery workers. ${ }^{18}$ However, a case-control study nested within the Swedish cohort did not reveal any specific occupational risk factors for STS. ${ }^{19}$ Risk excesses for multiple myelomas and sinonasal cancer were also found in the Swedish cohort, but based on few cases. ${ }^{18}$

The results of the epidemiological studies are thus quite inconsistent, and based on the data available in the mid1980s, the International Agency for Research on Cancer
(IARC) did not at that time find it possible to conclude whether leather tanning is associated with an excess risk of cancer. ${ }^{20}$

The aim of the present study was to assess how a 10 year extension of the follow up period affected cancer incidence in the Swedish leather tanning cohort.

\section{SUBJECTS AND METHODS}

Three Swedish leather tanneries were included in the study. The plants opened in 1860, 1897, and 1906 respectively. All three plants were closed down in the late 1980s or early 1990s (table 1). All three tanneries have performed both vegetable and chrome tanning.

In plant A chromium tanning had dominated, but a minor production of vegetable tanned leather continued until the late 1960s. Arsenic sulphides were used until about 1950. From the 1940s to about 1960, methyl mercury was used as fungicide, and from about 1950 to 1980 chlorophenols were used for the same purpose. Azo dyes were widely used during the entire production period, and benzidine dyes were used until 1980. Formaldehyde was extensively used for curing until the mid-1970s. The use of organic solvents, mainly butyl acetate, cyclohexanone, ethanol, ethyl acetate, ethylene glycol, methylethyl ketone, methylisobutyl ketone, toluene, and xylene, was at maximum during the 1970s. Toluene was contaminated with benzene up to the mid-1960s.

In plant $\mathrm{B}$ both chromium and vegetable tanning had occurred. Arsenic sulphides were used until the early 1950s. Methyl mercury compounds were used from the early 1940s until the beginning of the 1960s, when they were replaced by

Abbreviations: $\mathrm{Cl}$, confidence interval; $\mathrm{E}$, expected; $\mathrm{O}$, observed; SIR, standardised incidence ratio; STS, soft tissue sarcoma 


\section{Main messages}

- There was a slight overall increased risk for cancer among Swedish leather tannery workers.

- The increase in prostate cancer incidence might be a chance finding, but is noteworthy because it is in accordance with findings in a recent Swedish study.

- Numerical but non-significant increases in incidence were observed for soft tissue sarcomas, multiple myeloma, and sinonasal cancer.

chlorophenols that were used until about 1980. The use of organic solvents (petrol contaminated with benzene, trichloroethylene, and 1,1,1-trichloroethane) for degreasing of skin was considerably decreased during the 1980s. Azo and benzidine dyes were used for skin colouring. Formaldehyde curing was in use until 1975.

In plant $C$ the dominating product until 1960 was vegetable tanned sole leather. During the first half of the 1960s, the production changed to chrome tanned, coloured nappas, which lead to an increased consumption of organic solvents for coatings. Methyl mercury was used as a fungicide in the tanning process until the mid-1950s, when it was replaced by chlorophenols that were in use until 1979. Azo and benzidine dyes were used for skin colouring. A more detailed description of the plant specific production and exposures has been given in a previous publication. ${ }^{18}$

Name, date of birth, address, dates of start and end of employment, and workplace or job task for the blue collar workers were obtained through each of the three company records. The records included subjects employed from 1900 and onwards, but were not considered complete until 1930, 1946, and 1966 respectively (table 1).

Information on vital status and date of emigration was obtained from the Swedish Population Registry. For 92 of the workers the Swedish personal identification number was not complete, and they were therefore not included in the cohort. Moreover, 57 subjects were excluded since they had emigrated or died before the start of observation, and nine subjects were excluded because they were 80 years or older at start of observation. Thirteen persons were lost to follow up. The final cohort comprised 2027 workers employed for at least one year before 1987 (table 1). Vital status was determined as of 31 December 1999, and showed that 1230 workers were at that time still alive, 763 workers had died, and 34 workers had emigrated. The median year of birth in the cohort was 1927 (range 1878-1970). The median first year of exposure was 1955 (range 1902-1988), the median duration of employment was 6 years (range 1-64), and the median follow up time was 30 years (range $0.2-42$ ).

Information on malignant tumours for the period 195899, coded according to the International Classification of Diseases, seventh revision, was obtained from the National

\section{Policy implications}

- The enhanced prostate cancer incidence in the cohort during the 1990s raises the possibility that causative occupational agent(s) may still occur in the work environment of present day leather tanneries.

Swedish Cancer Registry. The cohort provided 56022 personyears under observation (table 1).

Expected cancer incidence for the observation period was calculated by means of the SYDCAP cohort programme using cause, calendar year, sex, and five year age group specific rates. These rates were calculated from incidence rates for specific malignant tumours and population counts, obtained from Statistics Sweden and the Swedish Cancer Registry. Date of death, date of emigration, date of second tumour, a person's 80th birthday, or end of observation period were used as individual endpoints, whichever occurred first. Cause specific standardised incidence ratios (SIRs) were calculated by dividing the observed numbers of incident cases with the expected numbers. The 95\% confidence intervals (95\% CIs) for the SIRs were calculated by treating the observed number as a Poisson variable, or as a normal variable if the observed value was greater than 15 . The term significant indicates that the $95 \%$ CI does not include 1.00 .

\section{RESULTS}

A slight but significant enhancement of the overall cancer incidence was observed (SIR 1.16, 95\% CI 1.04 to 1.29; table 2). Based on 59 cases, we found an increase in prostate cancer incidence (SIR 1.44, 95\% CI 1.10 to 1.86). Numerical, but non-significant increases, were observed for STS (SIR $2.62,95 \%$ CI 0.96 to 5.70 ), and multiple myeloma (SIR 1.65 , $95 \%$ CI 0.66 to 3.40 ). Incidences of lung, bladder, pancreatic, and renal cancer were not increased.

A comparison of the risk patterns during the first part of the follow up period 1958-89, which has been reported before, ${ }^{18}$ with those of the second part of the follow up period 1990-99, showed that the risk for prostate cancer was higher during the later period (SIR 1.70,95\% CI 1.12 to 2.47 ) than during the first one (SIR $1.28,95 \%$ CI 0.89 to 1.82 ; table 2). The patterns for STS, multiple myeloma, and sinonasal cancer were the opposite.

Excluding the first 20 years from the observation period, did not affect the overall cancer incidence (SIR 1.20, 95\% CI 1.07 to 1.34; table 3 ). The SIR for prostate cancer was not affected either (SIR 1.47, 95\% CI 1.10 to 1.91). The estimates for STS and multiple myeloma became slightly higher.

Workers with a minimum employment of 10 years had a slightly higher overall cancer incidence ( SIR 1.24, 95\% CI 1.06 to 1.44 ) than workers with a shorter employment (SIR 1.16, 95\% CI 0.98 to 1.30). There might be such an association between duration of employment and risk for STS, but

Table 1 Descriptions as of 31 December 1999 for 2027 workers employed for at least one year at any of three Swedish leather tanneries

\begin{tabular}{|c|c|c|c|c|c|c|c|}
\hline \multirow[b]{2}{*}{ Tannery } & \multirow[b]{2}{*}{ Tanning period } & \multirow{2}{*}{$\begin{array}{l}\text { Complete company } \\
\text { records }\end{array}$} & \multirow{2}{*}{$\begin{array}{l}\text { Cohort size } \\
\text { (males/females) }\end{array}$} & \multicolumn{3}{|c|}{ Vital status } & \multirow{2}{*}{$\begin{array}{l}\text { Person-years under } \\
\text { observation }\end{array}$} \\
\hline & & & & Alive & Dead & Emigrated & \\
\hline A & 1906-1988 & 1966 & $478(369 / 109)$ & 368 & 99 & 11 & 11085 \\
\hline B & 1897-1989 & 1930 & $924(579 / 345)$ & 514 & 398 & 12 & 28595 \\
\hline C & 1860-1991 & 1946 & $625(597 / 28)$ & 348 & 266 & 11 & 16342 \\
\hline Total & & & 2027 & 1230 & 763 & 34 & 56022 \\
\hline
\end{tabular}



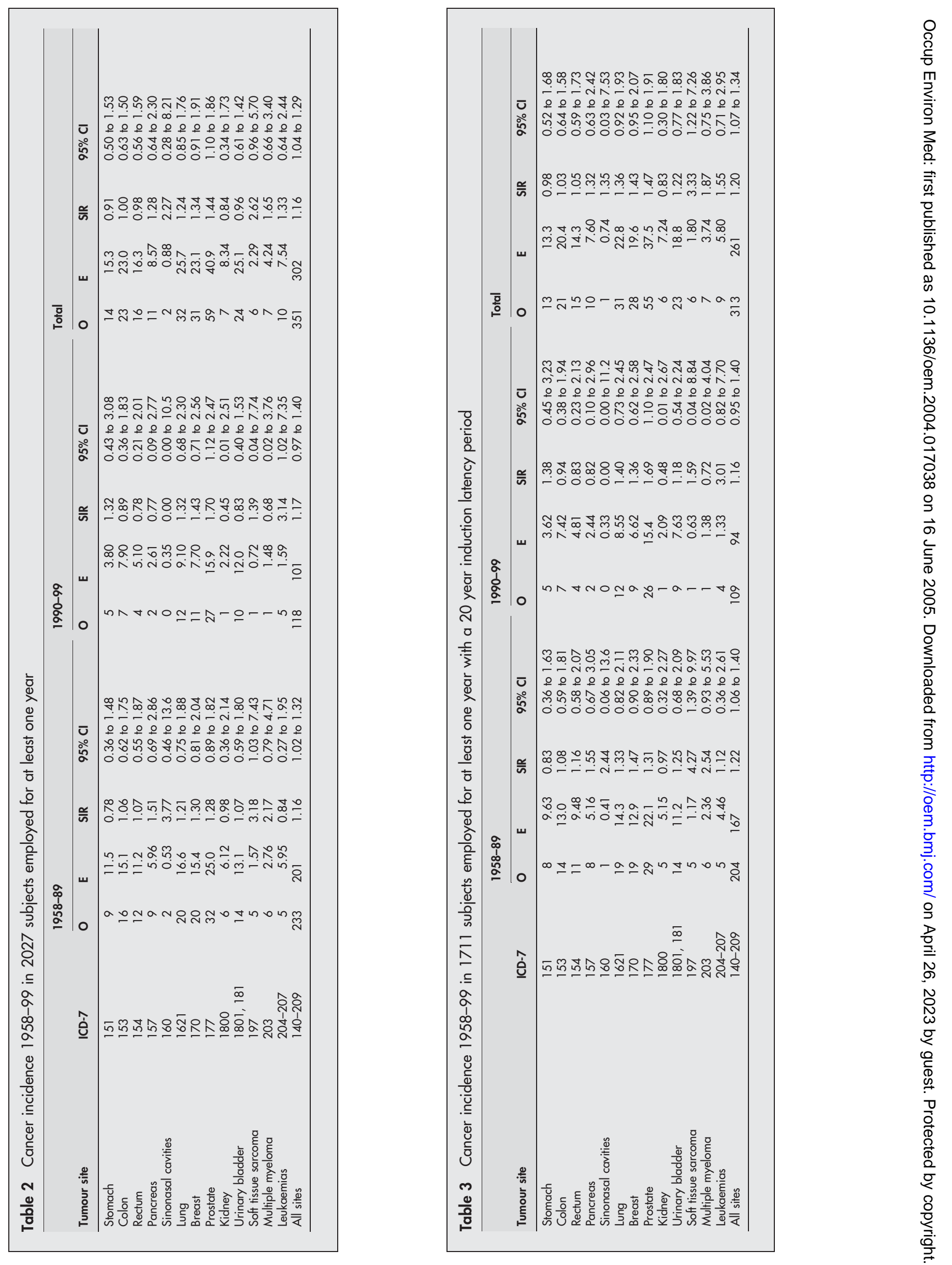
the incident cases were too few to make a meaningful interpretation (data not shown). No associations were found between length of employment and lung cancer, prostate cancer, or multiple myeloma (data not shown). The estimates were not affected by whether the workers had started their employment before or after 1950, with the exception of multiple myeloma. All seven observed cases of multiple myeloma occurred among workers first employed before 1950.

\section{DISCUSSION}

The main finding of the present study was the increased prostate cancer incidence, especially during the later part of the follow up period (1990-99). The risk estimate was, however, not enhanced by introducing a 20 year induction latency period, which can be interpreted either that the finding was not related to the work environment at all but rather an expression of simultaneous inference, or that the occupational agent(s) affected tumour promotion or progression rather than tumour initiation. The finding is, however, noteworthy, considering that the role of occupational exposures in prostate cancer aetiology is not well established. ${ }^{21}$ Increased estimates of prostate cancer among leather workers (SIR 1.58, 95\% CI 1.15 to 2.11 ) was also found in another Swedish study, linking Swedish national cancer incidence register data with employment data from the national census. ${ }^{22}$ The observations from the present study and the linkage study are in fact mostly independent, as only $20 \%$ of the prostate cancer cases in the present cohort were included in the Swedish linkage study. Furthermore, the Swedish linkage study showed enhanced risk for prostate cancer among agriculture workers. There are also a number of other epidemiological studies linking farming with prostate cancer. ${ }^{23-28}$ There are data indicating that pesticide handling has been responsible for this excess risk among farmers. ${ }^{28}$ Leather tanners have also been exposed to several pesticides. Unfortunately, the present study design did not allow evaluation of individual exposures to pesticides for the cohort subjects.

The increased incidences of STS, sinonasal cancer, and multiple myeloma were restricted to the first part of the follow up period (1958-89), which supports the fact that more recent occupational exposures in the leather tanning industry have not affected the incidence of these malignancies.

A strength of the study is the long follow up of the cohort. At the end of follow up 351 of 2027 subjects (17\%) were diagnosed with cancer, which gave a reasonably good statistical power to assess more common tumours such as prostate cancer. On the other hand, the power is still low for a detailed assessment of rarer tumours such as sinonasal cancer, multiple myeloma, and STS. The major limitation of this retrospective cohort analysis is the lack of information on specific work tasks and exposures for each subject in the cohort. An important reason for this is the very heterogeneous exposure situations, which have varied over the years and between the plants. Another reason is that the plants closed down during 1988-91. In connection with the previous follow up of this cohort, we performed a cohort based case-control study using interviews with former long term employees as a source for exposure assessment. ${ }^{19}$ As many of these key persons are no longer available, this is not a feasible way to assess exposure in the cohort.

In conclusion, the major result of the cohort follow up was a weak, but significant, increase in prostate cancer incidence among workers in the leather tanning industry, which corroborates the findings of a previous Swedish register linkage study. It cannot, however, be excluded that the results of the present study might be a random finding due to simultaneous inference.

\section{Authors' affiliations}

Z Mikoczy, L Hagmar, Department of Occupational and Environmental Medicine, Lund University Hospital, SE-221 85 Lund, Sweden

Funding: the work was supported by grants from the Klippan Leatherworker's Fund

Competing interests: none declared

\section{REFERENCES}

1 International Agency for Research on Cancer. IARC monographs on the evaluation of the carcinogenic risk of chemicals to humans-wood, leather and some associated industries. Vol. 25. Lyon: IARC, 1981.

2 Pippard EC, Acheson ED. The mortality of boot and shoe makers with special reference to cancer. Scand J Work Environ Health 1985:42:249-55.

3 Battista G, Comba P, Orsi D, et al. Nasal cancer in leather workers: an occupational disease. J Cancer Res Clin Oncol 1995;121:1-6.

4 Garabrant DH, Wegman DH. Cancer mortality among shoe and leather workers in Massachusetts. Am J Ind Med 1984;5:303-14.

5 Sweeny MH, Walrath J, Waxweiler J. Mortality among retired fur workers. Dyers, dressers (tanners) and service workers. Scand J Work Environ Health 1985; 11:257-64.

6 Coggon D, Pannett N, Osmond C, et al. A survey of cancer and occupation in young and middle aged men. I. Cancers of the respiratory tract. $\mathrm{Br} J$ Ind Med 1986;43:332-8.

7 Stern FB. Mortality among chrome tannery workers: an update. Am J Ind Med 2003;44:197-206.

8 Pippard EC, Acheson ED, Winter PD. Mortality of tanners. Br J Ind Med 1985;42:285-7.

9 Edling C, Kling $\mathrm{H}$, Flodin $\mathrm{U}$, et al. Cancer mortality among leather tanners. $\mathrm{Br} J$ Ind Med 1985:43:494-6.

10 Stern FB, Beaumont JJ, Halperin WE, et al. Mortality of chrome leather tannery workers and chemical exposure in tanneries. Scand J Work Environ Health 1987; 13:108-17

11 Cole P, Hoover R, Friedell GH. Occupation and cancer of the lower urinary tract. Cancer 1972;29:1250-60.

12 Vineis $\mathbf{P}$, Magnani $C$. Occupation and bladder cancer in males: a case-control study. Int J Cancer 1985;35:599-606.

13 Montanaro F, Ceppi M, Demers PA, et al. Mortality in a cohort of tannery workers. Occup Environ Med 1997;54:588-91.

14 Acheson ED, Pippard EC. Kidney cancer among leather workers. Lancet 1984;i:563.

15 Cartwright RA, Boyko RW. Kidney cancer among leather workers. Lancet 1984;i:850-1.

16 Malker HR, Malker BK, McLaughlin JK, et al. Kidney cancer among leather workers. Lancet 1984;i:56.

17 Seniori Costantini A, Paci E, Miligi L, et al. Cancer mortality among workers in the Tuscan tanning industry. Br J Ind Med 1989;46:384-8.

18 Mikoczy Z, Schütz A, Hagmar L. Cancer incidence and mortality among Swedish leather tanners. Occup Environ Med 1994;51:530-5.

19 Mikoczy Z, Schütz A, Strömberg U, et al. Cancer incidence and specific occupational exposure in the Swedish leather tanning industry: a cohort based case-control study. Occup Environ Med 1996;53:463-7.

20 International Agency for Research on Cancer. IARC monographs on the evaluation of the carcinogenic risk of chemicals to humans-overall evaluations of carcinogenicity: an updating of IARC Monographs Volumes 1 to 42, suppl 7. Lyon: IARC, 1987.

21 Parent M-É, Siemiatycki J. Occupation and prostate cancer. Epidemiol Rev 2001;23:138-43.

22 Sharma-Wagner S, Chokkalingam AP, Malker H, et al. Occupation and prostate cancer risk in Sweden. J Occup Environ Med 2000;42:517-25.

23 Keller-Byrne JE, Khuder SA, Schaub EA. Meta-analyses of prostate cancer and farming. Am J Ind Med 1997;31:580-6.

24 Acquavella J, Olsen $G$, Cole $P$, et al. Cancer among farmers: a meta-analysis. Ann Epidemiol 1998;8:64-74.

25 Cerhan JR, Cantor KP, Williamson K, et al. Cancer mortality among lowa farmers: recent results, time trends, and lifestyle factors. Cancer Causes Control 1998;9:311-19.

26 Buxton JA, Gallagher RP, Le ND, et al. Occupational risk factors for prostate cancer mortality in British Columbia, Canada. Am J Ind Med 1999;35:82-6.

27 Parker AS, Cerham JR, Putnam SD, et al. A cohort study of farming and risk of prostate cancer in lowa. Epidemiology 1999;10:452-5.

28 Settimi L, Macina A, Andrion A, et al. Prostate cancer and exposure to pesticides in agricultural settings. Int J Cancer 2003;104:458-61. 